\title{
CONTRIBUIÇÕES SOCIAIS NO ESTADO BRASILEIRO: DECORRÊNCIA DO PRINCÍPIO DA SOLIDARIEDADE
}

\section{SOCIAL TAXATION IN THE BRAZILIAN STATE: RESULT OF THE PRINCIPLE OF SOLIDARITY}

\author{
${ }^{1}$ Marcos André Alamy \\ ${ }^{2}$ Naiara Cardoso Gomide da Costa Alamy
}

\section{Resumo}

O Estado brasileiro caracteriza-se como estado de cunho social. Tal afirmativa decorre do próprio constitucional que elenca, expressamente, dentre suas normas amplo leque de direitos sociais. A efetivação de tais direitos depende de recursos que são obtidos do corpo social. $\mathrm{O}$ objetivo da pesquisa é verificar se as contribuições sociais desempenham um papel concretizador dos direitos sociais considerando o viés solidário da tributação, pois há vinculação de sua receita conforme comando constitucional. Para se alcançar o proposto foi utilizada a pesquisa bibliográfica e teórica por meio do método dedutivo.

Palavras-chave: Contribuições sociais; Estado brasileiro; Solidariedade; Direitos fundamentais; tributos.

\begin{abstract}
The Brazilian State is characterized as a state of social nature. This statement derives from the constitutional text that lists expressly among its laws wide range of social rights. The realization of these rights depends on resources that social taxation play a role concretizing social rights considering the solidary bias of taxation, because there linking its revenue as constitutional command. To achieve the proposed was used literature and theoretical research by the deductive method.
\end{abstract}

Keywords: Social taxation; State Brazilian; Solidarity; Fundamental rights; taxes.

\footnotetext{
${ }^{1}$ Mestre em Direito Público pela Universidade Estadual de Minas Gerais, UFMG - MG, (Brasil). Professor de direito tributário no Centro Educacional de São Gotardo, CESG - ES, (Brasil). Procurador da Câmara Municipal de Patos de Minas. Advogado. E-mail: malamy@ig.com.br

${ }^{2}$ Mestre em Direitos Fundamentais pela Universidade de Itaúna, UIT - MG, (Brasil). Professora de direito civil no Centro Educacional de Patos de Minas, IPE - MG, (Brasil). Advogada. E-mail: malamy@bol.com.br
} 


\section{INTRODUÇÃO}

O Estado, da maneira como é estruturado hoje, percorreu um grande caminho evolutivo para se configurar no desenho que se apresenta.

A Constituição é o documento jurídico responsável por seus contornos, ou seja, determina, seus alcances e limites para atuar perante a coletividade.

Dentre os papéis desempenhados pelo Estado encontra-se a atividade de instituir, arrecadar e fiscalizar a arrecadação de tributos. A atividade é considerada típica pois cabe somente ao Estado sua realização.

É interessante assinalar a relação entre a tributação e os direitos fundamentais. De um lado os direitos fundamentais interferem na fixação dos limites do poder de tributar e ao mesmo tempo que para a concretização de direitos fundamentais, principalmente dos denominados direitos de segunda dimensão, há a indispensabilidade da arrecadação de tributos para seu custeio.

O tema proposto é a investigação da natureza da contribuição social, enquanto espécie de tributo, e sua relação com princípio da solidariedade, objetivo fundamental da Constituição Federal brasileira.

A relevância do tema se encontra na necessidade de situar os cidadãos como pertencentes a uma mesma comunidade, no sentido de que, para se alcançar uma sociedade livre, justa e solidária é necessário que todos se unam em torno do mesmo objetivo, ou seja, o Estado só pode ser legítimo se os cidadãos estejam de acordo com as normas por ele impostas.

Desta forma, o estudo foi dividido em duas partes, sendo que, na primeira se discute a aplicação do princípio da solidariedade no Estado Democrático brasileiro, abordando a evolução do Estado e os valores que o alicerçaram em cada período distinto de sua evolução. A solidariedade, neste contexto, deve ser entendida como norma jurídica pois decorrente do próprio texto constitucional. Na sequência, se abordou as características das contribuições sociais, notadamente, sua ligação com a capacidade contributiva dos cidadãos e sua caraterística solidária oriunda da Constituição Federal.

No desenrolar deste estudo buscou-se privilegiar, na esteira de pensamento de Gustim e Dias (2014, p. 8), o enfoque metodológico baseado na multidisciplinaridade que carrega em si a mudança dos paradigmas da concepção tradicional. É pesquisa que contém caráter teórico e bibliográfico em que foi utilizado o método dedutivo com a finalidade de indicar a relação 
entre as assertivas genéricas e a conclusão específica, com base nas teorias existentes sobre o tema.

\section{O ESTADO BRASILEIRO E A APLICAÇÃO DO PRINCÍPIO DA SOLIDARIEDADE}

Historicamente o Brasil, considerando seu "descobrimento" e as peculiaridades de sua colonização, apresenta uma experiência democrática deficiente. Isto se reflete até nos dias atuais.

Apesar disto, tem-se hoje uma Constituição analítica que se caracteriza pela previsão de amplos direitos sociais que têm como objetivo a diminuição da desigualdade na sociedade brasileira.

A diminuição da desigualdade perpassa pela discussão sobre a detenção e efetivação dos direitos fundamentais. O Estado brasileiro ainda luta pela real implementação das previsões constitucionais no que se refere aos direitos fundamentais.

Doutrinariamente, os direitos fundamentais classificam-se como direitos de primeira, segunda, terceira, quarta e quinta dimensão.

Direitos de primeira dimensão são aqueles marcados pelo reconhecimento do princípio da liberdade e da igualdade formal. Manifestam-se com a finalidade de proteger o indivíduo contra o arbítrio do absolutismo. O reconhecimento desta dimensão encontrou ampla guarida no Estado liberal que se caracteriza por sua abstenção nas relações entre os membros do corpo social. Daí a denominação de direitos de cunho negativo.

Os direitos de segunda dimensão, denominados direitos sociais, associados à ideia de justiça social, estão intimamente ligados ao princípio da igualdade, do qual não podem se separar, pois fazê-lo equivaleria a desmembrá-lo da razão de ser que os ampara e estimula. (BONAVIDES, 2010, p. 564).

Os direitos sociais ligam-se ao Estado de bem-estar social e caracterizam-se por uma atuação positiva do Estado. Morais e Brum (2016, p. 13) asseveram que:

\footnotetext{
O arranjo político jurídico que se convencionou chamar 'Estado Social' ou " estado de Bem-estar Social' - tomando aqui genericamente -, surgido no transcurso da primeira metade do século XX e impulsionado após a Segunda Guerra Mundial, é o resultado do reconhecimento e da positivação dos direitos relativos às relações de produção e seus reflexos. É aquele Estado no qual as pessoas, independentemente de sua situação social, ostentam direitos que devem ser protegidos por meio de prestações públicas (saúde, previdência, moradia, ou seja, os chamados direitos sociais, prestacionais por excelência).
} 
Estes direitos buscam demonstrar a injustiça social e visam assegurar os direitos àqueles que não os tem, visando diminuir a distância entre os detentores de direitos e aqueles em situação de exclusão. Ao Estado, então, cabe o cumprimento de prestações positivas por meio do cumprimento de políticas públicas que busquem a efetivação da igualdade, considerada sob seu viés material.

A concretização destas ações depende da efetiva contribuição da sociedade, demandando, obviamente, da disponibilidade de recursos suficientes para que as prestações possam ter o resultado esperado. Assim, o Estado deve se municiar de mecanismos hábeis visando a arrecadação desses recursos.

Caracterizam-se os direitos de terceira dimensão pela solidariedade. Os direitos de terceira dimensão ligam-se à proteção de grupos humanos, ou seja, sua característica predominante reside em sua titularidade coletiva ou difusa, e são denominados de direitos de solidariedade ou fraternidade. (SARLET, 2010, p. 48).

Nascem os direitos fundamentais de terceira geração, conforme ensinado por Paulo Bonavides, da consciência da divisão do mundo entre países desenvolvidos e países em desenvolvimento. (BONAVIDES, 2010, p. 569).

$\mathrm{O}$ traço que diferencia os direitos de terceira dimensão das dimensões anteriores reside em sua natureza coletiva que para serem efetivados necessitam de novas metodologias de garantia e proteção. Desta realidade surge a tutela coletiva processual que tem sua gênese no próprio texto constitucional.

Conforme Morais e Streck (2010, p.100-104):

Quando assume o feitio democrático, o Estado de Direito tem como objetivo a igualdade e, assim, não lhe basta a limitação ou a promoção da atuação estatal, mas referenda a pretensão à transformação da sociedade não estando mais atrelada inelutavelmente à sanção ou à promoção. O fim a que se pretende é a constante reestruturação das próprias relações sociais. [...] À diferença dos modelos anteriores, o Estado Democrático de Direito, mais do que uma continuidade, representa uma ruptura, porque traz à tona, formal e materialmente, a partir dos textos constitucionais diretivos e compromissórios, as condições de possibilidade para a transformação para a realidade.

Vê-se, então a terceira dimensão de direitos fundamentais traz grandes avanços no que se refere à abrangência da detenção de direitos. Não mais apenas a possibilidade de gozo e fruição de direitos fundamentais na seara individual, mas também na seara coletiva que inclui 
pessoas antes marginalizadas pelo sistema, seja por carência econômica, educacional, ou de qualquer outra natureza.

No que se refere à relação dos direitos fundamentais com a tributação entende-se que, conforme Costa (2014, p.28):

\begin{abstract}
Consideramos remarcar que a compreensão do Direito Tributário, cada vez mais, está voltada à preocupação concernente à adequação da tributação ao exercício de direitos fundamentais. De fato, universalmente vem se afirmando uma visão humanista da tributação, a destacar que essa atividade estatal não busca apenas gerar recursos para o custeio de serviços públicos mas, igualmente, o asseguramento do exercício de direitos públicos subjetivos.
\end{abstract}

Disto decorre a relação entre a tributação e a efetivação dos direitos sociais no sentido de que por meio da atividade tributária do Estado, caracterizada como instrumento, pode-se alcançar a concretização de direitos fundamentais, no caso, direitos de cunho social.

\title{
1.1 O princípio da solidariedade
}

O reconhecimento expresso do princípio da solidariedade no art. $3^{\circ}$, I, da Constituição Federal, trouxe uma nova maneira para interpretar o ordenamento jurídico. Isto decorre do fato que tal princípio é objetivo fundamental da República Federativa do Brasil.

A solidariedade, então, surge como expressão de direito fundamental que visa concretizar ações que buscam reduzir as desigualdades. Estas ações uma vez exteriorizadas revestem-se de características solidárias.

Nesta esteira de pensamento, Sarmento (2010, p. 295) ensina, sobre o princípio da solidariedade, que:

[...] é possível afirmar que quando a Constituição estabelece como um dos objetivos fundamentais da República brasileira "construir uma sociedade justa, livre e solidária”, ela não está apenas enunciando uma diretriz política desvestida de qualquer eficácia normativa. Pelo contrário, ela expressa um princípio jurídico, que, apesar da sua abertura e indeterminação semântica, é dotado de algum grau de eficácia imediata e que pode atuar, no mínimo, como vetor interpretativo como um todo.

A Ministra Carmen Lúcia, em voto proferido na Ação Direta de Inconstitucionalidade $\mathrm{n}^{\circ} 2649$, destacou o princípio da solidariedade nos moldes propostos neste estudo. 
não se pensa ou age segundo o ditame de 'a cada um o que é seu', mas 'a cada um, segundo a sua necessidade'. E a responsabilidade pela produção destes efeitos sociais não é exclusiva do Estado, senão que de toda a sociedade. (BRASIL. Supremo Tribunal Federal. Adi n ${ }^{\circ}$ 2649. Relator: Ministra Carmen Lúcia. Brasília, DF, 08 de janeiro de 2008. Diário Judiciário Eletrônico. Brasília, 17 out. 2008. Disponível em: <www.stf.jus.br>. Acesso em: 15 jun. 2016.)

A solidariedade constitui um dos valores mais caros no que se refere à conquista de direitos fundamentais, pois, conforme já afirmado anteriormente, tanto a liberdade quanto a igualdade só podem ser efetivadas sob uma nova ótica que, indiscutivelmente, deve perpassar por uma interpretação marcada por ideais solidários ainda mais em face dos novos direitos produzidos por uma sociedade complexa.

Diante das reflexões acima apresentadas sobre a solidariedade pode se afirmar que seu sentido e aplicação serve como caminho para nortear a titularidade de direitos por meio do reconhecimento de deveres.

Morais e Brum (2016, p. 54-55), com base na obra de Luciano Violante, aponta a preocupação de que o reconhecimento constante de direitos sem a correspondência com seus deveres legitima o egoísmo individual, pois ao atendimento pontual de direitos afetados pela lógica da globalização e a incapacidade do Estado em cumprir com as promessas constitucionalmente assumidas, leva o indivíduo a priorizar apenas seus desejos.

Solidariedade é conceito que pode ser conceituado em diversos níveis distintos. O que interessa neste estudo é seu caráter normativo. Mas, não se pode deixar de abordar seu viés ético, que se exterioriza no altruísmo, e seu viés moral, que se caracteriza pela caridade e generosidade. Pode-se perceber a carga de conteúdo valorativo do princípio da solidariedade, pois mesmo que haja a identificação de diferentes níveis conceituais, a norma jurídica solidariedade carrega em si conteúdo ético.

O conteúdo aberto do princípio da solidariedade possibilita que sua utilização seja realizada de maneira que sua substância seja adaptada a situações diversas. O que pode gerar abusos na utilização do princípio.

Neste sentido, Marcelo Neves cita como exemplo parecer $^{3}$, da procuradoria geral da república, na $\mathrm{APF} \mathrm{n}^{\circ} 54$ que contém considerações sobre o princípio da solidariedade sem

\footnotetext{
${ }^{3}$ Neves, Marcelo. Entre hidra e Hércules. 2 ed. São Paulo: Editora WMF Martins Fonseca, 2014. p. 219.A Arguição de Preceito fundamental $n^{\circ} 54$ tratou da controvérsia sobre o direito de interrupção da gravidez em caso de feto anencefálico. No parecer em questão há a invocação do princípio da solidariedade para argumentar contra o aborto dos fetos anencéfalos, e sugerir que da continuidade da gravidez os bebês nascidos poderiam ser doadores para outras crianças que necessitassem de órgãos. Conforme Neves, este é um exemplo do uso do princípio da solidariedade em desarticulação com os outros princípios e regras que embasam o caso concreto.
} 
contornos definidos. Alerta que o princípio hoje tem sido utilizado, por seu forte apelo retórico, como solução para todos os problemas constitucionais relevantes e para sua correta invocação é necessário que seja aplicado em articulação com as outras normas que incidem no caso concreto. (NEVES, 2014, p. 219).

A relevância da aplicação do princípio da solidariedade não pode ser ignorada, principalmente, por ser instituto competente para a revitalização dos direitos de liberdade e igualdade, expoente dos direitos, respectivamente, de primeira e segunda dimensão.

A abertura semântica do princípio da solidariedade possibilita sua aplicação em casos diversos. Entretanto e em decorrência dessa abertura, é importante sua análise e estudo, não sendo devida sua utilização sem limites e desarticulada das regras e demais princípios que integram a Constituição Federal.

O princípio da solidariedade, desta forma, deve ser percebido como direito, mas também como dever. Com esta indicação para compor seu conteúdo pode-se caminhar em direção a uma sociedade mais igualitária.

\section{AS CONTRIBUIÇÕES SOCIAIS E SUA IMPORTÂNCIA PARA O ESTADO}

A necessidade de tributação é decorrência da própria organização do homem em sociedade. Até mesmo nas sociedades mais primitivas é possível notar a presença da tributação - o produto da caça, por exemplo, era distribuído com a tribo.

$\mathrm{O}$ atendimento das necessidades do Estado, entendido como instituição indispensável à existência de uma sociedade organizada (PALSEN, 2014, p. 15), pressupõe a disponibilidade de recursos. O Estado, seja ele totalitário ou democrático, depende de recursos diversos para manutenção de sua estrutura e, principalmente, para realizar seus objetivos.

Assim, embora não seja a única fonte de financiamento das atividades estatais, a tributação atinge maior ou menor importância, dependendo do modelo estatal. Por óbvio, no modelo socialista, onde o Estado é dono de todas as fontes de produção, a tributação tem papel secundário. De outra sorte, o modelo capitalista tem nos tributos sua principal fonte de financiamento.

No Estado Liberal clássico, que tem como primados a propriedade privada e a liberdade econômica, a interferência do Poder Público deve ser mínima. Por conseguinte, a tributação também não deverá ser excessiva. Até porque não há comprometimento com políticas sociais. 
No Estado Social, por sua vez, o tributo legitima-se como instrumento de repartição e de equilíbrio da sociedade. Logo, a tributação é elevada.

Os dois modelos gozam de pontos fracos e pontos fortes, sendo possível afirmar que ambos estão em crise. Se por um lado, o modelo Liberal reproduz desigualdade social, por outro o Social onera excessivamente a economia e, por conseguinte, as famílias.

Nos Estados democráticos, as constituições, ao ponto que traçam seus objetivos, apresentam a formatação do Poder de tributar e, em seguida, cuidam de limitar esse Poder.

O Estado Democrático brasileiro apresenta características tanto do Estado liberal quanto do Estado social. A busca por uma sociedade mais justa impulsionou o constituinte originário por estabelecer um modelo (já bastante alterado desde a promulgação da Constituição) que privilegiasse a construção de uma sociedade menos desigual.

O estabelecimento do princípio da solidariedade como objetivo fundamental, no título I do texto constitucional autoriza a interpretação de que ele influenciará a aplicação das normas constitucionais e servirá como vetor de aplicação na condução dos negócios estatais.

O rompimento com a ordem constitucional anterior, neste contexto, é drástico pois os cidadãos recebem um novo texto constitucional, carregado de altos valores morais, que carecem de aplicação imediata diante da realidade fática brasileira vivida.

No campo tributário, a Constituição Federal de 1988 acompanhou o que já era pacífico no campo doutrinário e jurisprudencial, incorporando ao nosso sistema tributário as contribuições especiais e os empréstimos compulsórios. Desde então, restaram superados os critérios estabelecidos no caput do artigo $4^{\circ}$ do Código Tributário Nacional, e em seu inciso I, para definição da espécie tributária.

Pela leitura do CTN, a espécie tributária deveria ser definida, simplesmente, a partir da análise do fato gerador. Se o fato gerador estivesse vinculado a serviços públicos ou ao exercício do poder de polícia, estaríamos diante de taxa. Se o fato gerador estivesse vinculado à obra pública, o tributo seria a contribuição de melhoria. Por conseguinte, não havendo vinculação do fato gerador a atividade estatal, caracterizar-se-ia o tributo como imposto.

Com o reconhecimento constitucional das contribuições especiais e dos empréstimos compulsórios, a finalidade legal do produto da arrecadação, também, passou a ser primordial para se definir a espécie tributária.

A Constituição de 1988, ao passo que encampou as contribuições como espécies tributárias, de atribuir à União, a competência exclusiva, admitidas exceções, para instituir contribuições sociais, de intervenção no domínio econômico e do interesse de categorias 
profissionais. Ainda, trouxe maiores facilidade para criação de contribuições especiais que as facultadas a outras espécies tributárias. A exemplo, desnecessidade de Lei Complementar prevendo a base de cálculo, fato gerador e sujeito passivo da obrigação tributária decorrente de contribuições.

A Constituição, também, dotou a União de competência residual para criação de novas contribuições especiais que, inclusive, podem ter a mesma base de cálculo e fato gerador de impostos já descrito no texto constitucional.

Portanto, o Sistema Tributário Nacional, com o novo cenário pós Constituição de 1988, culminou em estimular o aumento significativo da espécie tributária em estudo.

Natural, então, que os gestores públicos, em busca do atingimento dos objetivos do Estado, delineados pela Constituição, se valessem das prerrogativas constitucionais e propiciassem um crescimento exponencial da representatividade, em termos de volume de arrecadação, das contribuições em face dos demais impostos.

A arrecadação da União, antes da promulgação da Constituição, tinha como principal fonte os impostos, ao lado das contribuições sociais voltadas para seguridade social subespécies de contribuições especiais, mas com finalidade específica para custeio da previdência.

Na década de 1990 foram instituídas novas contribuições no Brasil e, sobretudo, no ano de 1999, a importância das contribuições sociais gerais para arrecadação havia crescido sobremaneira, já se aproximando do volume decorrente de impostos.

O fato de os recursos arrecadados com as contribuições sociais não integrarem o montante a ser repartido com os demais entes da Federação e considerando o radical incremento nos valores arrecadados - além da criação de novas contribuições, houve o aumento significativo das alíquotas das contribuições já criadas - pode ser considerado fundamental para os avanços nas políticas públicas de saúde e, principalmente, de assistência social verificados no início do Século XXI.

Tal situação se deve, justamente, à natureza das contribuições sociais, cujos recursos devem ser integralmente despendidos com finalidade social. Desta forma, é possível verificar, mais que em outras espécies e subespécies tributárias, a presença marcante no Princípio da Solidariedade na configuração das contribuições sociais.

\subsection{Princípio da Solidariedade, o dever de tributar e as contribuições sociais}


Nos dias atuais, embora muito se reclame da elevada carga tributária, é pacífico o reconhecimento da necessidade da tributação. É indiscutível que a tributação, seja do patrimônio, seja da atividade produtiva, seja da renda, é totalmente concordante com quaisquer estratégias de desenvolvimento econômico e social da sociedade.

A tributação é de tal sorte importante que é imperioso afirmar que tributos e economia de mercado são indissociáveis. Pode até haver discussão quanto á eficiência ou não dos Estados na aplicação de seus recursos, mas não há, até hoje, quaisquer possibilidades de se pregar a não cobrança de tributos.

A Constituição Federal de 1988, imbricada diretamente com o objetivo de construir uma sociedade livre, justa e solidária, assegura um conjunto de direitos e, ao mesmo tempo, traça mecanismos que permitem viabilizar tal objetivo.

A Solidariedade, direito de terceira geração e que deve ser percebida a partir de uma visão altruísta, indica que a paz social somente será atingida com a diminuição das desigualdades.

A fim de dotar o Estado, de forma eficiente, de instrumentos hábeis à promoção da igualdade, há necessidade premente de recursos. Não há boa governança, não há governo eficaz, se não houver recursos suficientes para sua automanutenção e para o atendimento das necessidades da coletividade.

Tal constatação não se confunde com a defesa de uma elevada carga tributária. Até porque, o aumento de tributos, além da capacidade contributiva das famílias, pode implicar em recessão e, por conseguinte, ter efeito contrário diminuindo a arrecadação.

O que se deve ter em mente é que a tributação deve se dar em absoluta consonância com a capacidade contributiva, obedecendo princípios básicos da seletividade com objetivos extrafiscais, não se perdendo de vista que a finalidade de aumentar a arrecadação deve ser, justamente, a promoção de justiça social. Isto, em consonância com o Princípio da Solidariedade.

Fábio Sabbag (2015, p. 194) ressalta a vinculação da capacidade contributiva à necessidade de arrecadação suficiente para atendimento das demandas da coletividade:

De fato, a implementação do critério de distinção, para fins de aferição da real capacidade contributiva, está intimamente ligada ao modo como o Estado recebe os recursos necessários ao atendimento das necessidades coletivas. Não basta arrecadar a receita, mas "arrecadar a receita exigida pela justiça" 
O citado autor, ainda, atrela o princípio da capacidade contributiva a aspectos relacionados à justiça distributiva e à igualdade:

\footnotetext{
Atuando positivamente, na esteira da concretização da justiça distributiva, ínsita ao postulado da capacidade contributiva, o legislador deverá procurar criar o que Casalta Nabais denomina "mínimo de igualdade", em duas perspectivas:

(I) o mínimo de igualdade como ponto de partida, que se mostra como a forma isonômica de concessão de oportunidades ou chances, à luz do grau de satisfação das necessidades primárias dos indivíduos (alimentação, vestuário, habitação, saúde etc.);

(II) o mínimo de igualdade como ponto de chegada, ou seja, a própria igualdade de resultados, dependente sobretudo da satisfação das mencionadas necessidades primárias. (SABBAG, 2015, p. 197).
}

A satisfação universal de necessidades primárias é o ponto inicial, o primeiro passo, para concretização dos ideais de fraternidade.

Compulsando detidamente as espécies e subespécies tributárias, não há dúvidas que as contribuições sociais são as que gozam, com maior intensidade, de natureza solidária.

Não se pode olvidar, que os impostos, cuja arrecadação deve ser destinada ao financiamento de serviços universais, são também, de tal sorte, formulados com fundamento na solidariedade social. Não possuem caráter retributivo, mas sim contributivo.

Considerando a não vinculação das receitas dos impostos, com as exceções constitucionais, é notória a presença dos ideais de solidariedade na cobrança dos impostos.

No entanto, a arrecadação dos impostos, não havendo destinação legal específica, é regularmente utilizada para manutenção da máquina administrativa. É com os recursos de impostos é que são custeadas, em sua maior parte, as despesas dos poderes legislativo e judiciário, por exemplo.

Deste modo, com a receita de contribuições sociais, com destinação legal determinada, é possível fazer novos investimento, manter programas sociais e de saúde pública capazes de combater as desigualdades e, ainda custear a seguridade social.

No campo jurisprudencial, há algum tempo, o princípio da solidariedade costuma ser invocado como determinante da obrigação de toda sociedade contribuir com a promoção da ordem social, principalmente com o custeio da seguridade social.

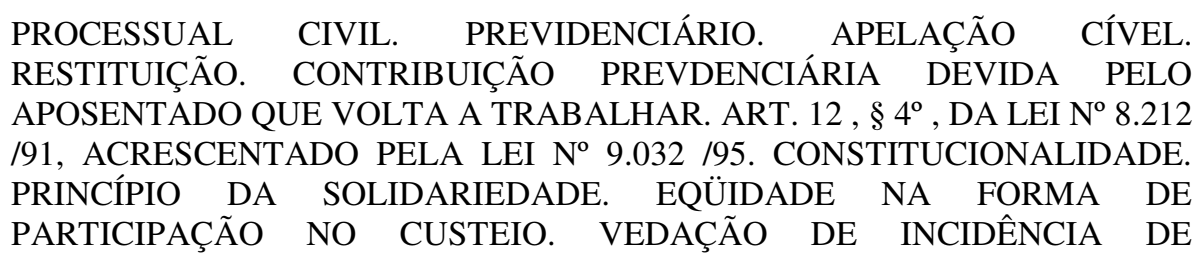


CONTRIBUIÇÃO SOBRE OS PROVENTOS E PENSÕES. IMUNIDADE INTERPRETADA RESTRITIVAMENTE. CONFISCO INEXISTENTE. OBRIGATORIEDADE DA FILIAÇÃO À SEGURIDADE SOCIAL. - O artigo 12 , $\S 4^{\circ}$ da Lei n..$^{\circ} 8.212$ /91, inserido pela Lei n. ${ }^{\circ} 9.032$ /95, dispõe que "O aposentado pelo Regime Geral de Previdência Social-RGPS que estiver exercendo ou que voltar a exercer atividade abrangida por este Regime é segurado obrigatório em relação a essa atividade, ficando sujeito às contribuições de que trata esta Lei, para fins de custeio da Seguridade Social". - A cobrança desta exação encontra respaldo em vários princípios constitucionais estruturantes do Sistema Nacional de Seguridade Social. Em primeiro lugar, de se destacar que tal exação encontra validade constitucional no chamado princípio da solidariedade, nos termos do artigo 195, caput, da Constituição Federal, através do qual toda a sociedade, direta ou indiretamente, é chamada a contribuir para o custeio da Seguridade Social. - Estabelece o art. 194 , inciso V, da Constituição Federal , o princípio da capacidade contributiva especificamente em seara previdenciária. Tal dispositivo dá concreção particularizada ao que dispõe o art. $5^{\circ}$, em seu caput: "todos são iguais perante a lei, sem distinção de qualquer natureza". - Esse preceito, basilar em nossa ordem constitucional, busca garantir o valor igualdade em nosso regime jurídico. Todavia, não tem como escopo uma garantia apenas formal de igualdade, mas, sobretudo, busca implementar a igualdade material em nossa ordem social. - E, no caso em exame, vê-se que não se pratica uma forma desarrazoada de discriminação. É que o aposentado que volta a trabalhar. (TRF-3 APELAÇÃO CIVEL - 1065138 : AC 46169 SP 2005.03.99.046169-1.Relatora: Juiza Suzana Camargo. Julgamento: 02/10/2006. Publicação no DJU em 19/01/2007, p. 346). Disponível em: <www.jfsp.jus.br>. Acesso em: 15 jun. 2016.)

Em decorrência do Princípio da Solidariedade, todos temos deveres uns com os outros. A paz social, tão propalada, somente será possível ante um crescimento econômico e social que abarque a diminuição das desigualdades.

Solidariedade e fraternidade não se confundem com caridade. A busca individual por qualidade de vida perpassa, necessariamente, pela melhoria da qualidade de vida de toda coletividade.

Não se trata de pregar a igualdade formal ou retomar discussões sobre a viabilidade de se construir uma sociedade comunista. O que se constata é que apenas com a redução das desigualdades, com políticas públicas eficientes e economia forte, é possível vislumbrar a paz social.

Pobreza gera violência. Violência gera intranquilidade. Deficiência de educação e de formação profissional geram mão de obra de má qualidade. Mão de obra de má qualidade impede avanços nos meios de produção. Enfim, tudo está intrinsicamente ligado.

Empresas de grande porte se reportam e buscam se tornar solidárias não por mero capricho ou estratégia de marketing. A solidariedade é o caminho para o crescimento equânime e seguro.

Em um sistema capitalista, com economia forte e pujante, é necessário que os recursos tributários sejam investidos, de maneira correta, em políticas públicas voltadas a propiciar o 
bem-estar do cidadão. O aumento da produção e, consequentemente, o aumento da renda das famílias redundam em maior arrecadação do Estado.

Havendo tributos cujos recursos sejam canalizados para a área social, é possível que o Estado participe, ainda mais, desse círculo virtuoso, contribuindo para a formação de uma sociedade livre, justa e solidária.

Nessa esteira, as contribuições sociais foram constitucionalmente definidas a partir da destinação que deve ser dada à sua arrecadação que devem, justamente, atender promoção da ordem social.

Luciano Amaro (2008, p. 53) assim aborda o tema:

[...] a Constituição caracteriza as contribuições sociais pela sua destinação, vale dizer, são ingressos necessariamente direcionados a instrumentar a atuação da União no setor da ordem social.

Assim dispõe o texto Constitucional:

Art. 149. Compete exclusivamente à União instituir contribuições sociais, de intervenção no domínio econômico e de interesse das categorias profissionais ou econômicas, como instrumento de sua atuação nas respectivas áreas, observado o disposto nos arts. 146, III, e 150, I e III, e sem prejuízo do previsto no art. $195, \S 6^{\circ}$, relativamente às contribuições a que alude o dispositivo.

Vale anotar que a própria Constituição caracterizou as contribuições como "instrumento" de atuação "nas respectivas áreas". Logo, as contribuições sociais devem ser instrumento de atuação na área social, delimitando a utilização de seus recursos, de acordo com a lei instituidora e em consonância com os preceitos constitucionais.

Neste sentido, Regina Helena Costa (2014, p. 151) ensina:

\begin{abstract}
As contribuições sociais constituem instrumentos de atuação da União na área social. Para delimitar-se o domínio dentro do qual se autoriza a instituição de contribuições dessa natureza, impõe-se a remissão ao título da Ordem Social no Texto Fundamental (arts. 193 a 232). Assim, as contribuições sociais podem ser instituídas para alcançar finalidades relativas à seguridade social, à educação, à cultura e ao desporto, à ciência e à tecnologia, à comunicação social, ao meio ambiente, à família, à criança, ao adolescente, ao idoso e aos índios.
\end{abstract}

$\mathrm{Na}$ trilha dos avanços na área econômica vividos até primeira década do século XXI, o incremento na arrecadação das contribuições sociais teve papel fundamental para propiciar a criação de programas de distribuição de renda e ainda de projetos voltados para formação 
profissional e educacional do cidadão. Tivemos resultados magníficos que demonstram que o caminho escolhido poderia ser eficaz.

Entretanto, além do pressuposto da existência de bons programas é essencial que a política econômica e social de um governo caminhe pari passu com sua política fiscal. Aliás, a política fiscal deve ser utilizada na condução da política econômica. Os resultados desastrosos da economia nacional não são reflexos diretos de programas sociais, em primeira análise, mas sim de absoluto descontrole das contas públicas, do desiquilíbrio entre a receita e a despesa.

Tal colocação é feita com o propósito de não renegar a importância da continuidade de programas sociais, custeados com recursos de contribuições, e que guardam enorme consonância com os objetivos da República Federativa do Brasil, dentre eles, o atendimento à solidariedade.

\section{CONCLUSÃO}

A solidariedade é objetivo fundamental previsto na Constituição Federal e influencia todo o ordenamento jurídico. Sua aplicação, no campo tributário atinge extrema relevância pois visa a redução das desigualdades sociais. Ou seja, existe uma relação estreita entre a concretização de direitos fundamentais sociais e atividade tributária do Estado.

A Constituição Federal de 1988 disciplinou, de maneira vasta, a detenção dos direitos sociais. A efetivação destes direitos depende da arrecadação, pelo Estado, de recursos para sua implementação e concretização.

Assim, a solidariedade aplicada na concretização dos direitos sociais apresenta caráter

tanto de direito como de dever. É princípio que traz em sua essência esta dupla orientação com a finalidade de se concretizar uma sociedade mais justa e igualitária.

Desta forma, a contribuição de cada um dos integrantes da sociedade ao Estado é decorrência lógica da própria organização desta mesma sociedade.

No atual Estado brasileiro a Constituição equilibra características antagônicas que buscam a efetivação dos direitos sociais com a conjugação de ideais liberais, e para a harmonização deste aparente conflito na escolha de valores é necessária a aplicação do princípio da solidariedade, considerado como normas de observância indispensável, que apresenta a finalidade de realizar os fins do Estado. 
As contribuições sociais, neste contexto, assumem relevância significativa pois destinadas às finalidades sociais. Ou seja, a razão de criação da contribuição social está assentada em sua gênese solidária.

Além de gozarem de natureza contributiva, a vinculação da receita advinda das contribuições sociais é atrelada à promoção da ordem social. Tal fato, concretiza a solidariedade enquanto princípio constitucional.

O princípio da solidariedade é, também, informador de outras espécies tributárias, a exemplo dos impostos. No entanto, nas contribuições sociais, sobretudo em função do caráter de referibilidade específica, é tema em que a solidariedade se assenta da maneira mais escorreita para validar a cobrança.

A promoção da ordem social, estampada na Constituição, depende intrinsicamente da arrecadação derivada das contribuições sociais.

Por todo o exposto, pode-se afirmar que as contribuições sociais se caracterizam como veículos de concretização do princípio da solidariedade.

\section{REFERÊNCIAS}

AMARO, Luciano. Direito Tributário Brasileiro. 14. ed. São Paulo. Saraiva, 2008.

ARENDT, Hannah. Entre o passado e o futuro. 5 ed. 3 reimp. São Paulo: Perspectiva, 2005.

BOBBIO, Norberto. A era dos direitos. Nova Ed. 13 reimpressão. Rio de Janeiro: Elsevier, 2004.

BONAVIDES, Paulo. Curso de Direito Constitucional. 25 ed. São Paulo: Malheiros Editores, 2010.

COSTA, Regina Helena. Curso de Direito Tributário. 4 ed. São Paulo: Saraiva, 2014.

DALLARI, Dalmo de Abreu. Elementos de Teoria Geral do Estado. 32 ed. São Paulo: Saraiva, 2013.

FERRAJOLI, Luigi. Por uma teoria dos direitos e bens fundamentais. Porto Alegre: Ed. Livraria do Advogado, 2011.

GUSTIM, Miracy Barbosa de Sousa; DIAS, Maria Teresa Fonseca. (Re)pensando a pesquisa jurídica. 4 ed. rev..e atual. Bel Horizonte: Del Rey, 2013.

MORAES, Maria Celina Bodim de. O princípio da solidariedade. Disponível em: <htpp://www.idcivil.com.br./pdf/biblioteca9.pdf>. Acesso em 15 abr. 2014. 
MORAIS, Jose Luis Bolzan de. O estado democrático de direito e o "museu da teoria do estado! s.n.t.

MORAIS, Jose Luis Bolzan de; BRUM, Guilherme Valle. Políticas Públicas e jurisdição constitucional: entre direitos, deveres e desejos. Porto Alegre: Livraria do Advogado Editora, 2016.

NEVES, Marcelo. Entre a hidra e Hércules. Princípios e regras constitucionais como diferença paradoxal no sistema jurídico. 2 ed. São Paulo: Editora WMF Martins Fontes, 2014.

PAULSEN, Leandro. Curso de Direito Tributário. 6 ed. Porto Alegre. Livraria do Advogado. 2014.

QUEIROZ, Cristina. Direitos Fundamentais Sociais. Coimbra: Coimbra Editora, 2006.

RODOTÁ, Stefano. Solidarietà. Un'utopia necessária. Roma: Laterza, 2014.

SABBAG, Eduardo. Manual de Direito Tributário. 7 ed. São Paulo: Saraiva, 2015.

SARLET, Ingo Wolfgang. A eficácia dos direitos fundamentais. Uma teoria geral dos direitos fundamentais na perspectiva constitucional. 10 ed. ver. atual. e ampl. Porto Alegre: Livraria do Advogado Editora, 2010.

SARMENTO, Daniel. Direitos fundamentais e Relações Privadas. 2 ed. Rio de Janeiro: Lumen Juris, 2010.

TOMAZ, Carlos Alberto Simões de. Constituição, política e a ordem internacional heterárquica. Uma reflexão a partir da visão pragmático-sistêmica de Luhmann. Curitiba: Editora CRV, 2011. 